\title{
Lack of association between the MDM2 promoter polymorphism SNP309 and clinical outcome in chronic lymphocytic leukemia
}

\author{
Mohd Arifin Kaderi ${ }^{a}$, Mahmoud Mansouri ${ }^{a}$, Norafiza Zainuddin ${ }^{b}$, Nicola Cahilla, \\ Rebeqa Gunnarsson ${ }^{\mathrm{c}}$, Mattias Jansson ${ }^{\mathrm{a}}$, Eva Kimby ${ }^{\mathrm{d}}$, Anna Åleskog ${ }^{\mathrm{e}}$, Jeanette Lundinn ${ }^{\mathrm{f}}$, \\ Bengt Glimelius ${ }^{\mathrm{b}, \mathrm{g}}$, Mads Melbye ${ }^{\mathrm{h}}$, Gunnar Juliusson ${ }^{\mathrm{c}}$, Jesper Jurlander ${ }^{\mathrm{i}}$, Richard Rosenquist ${ }^{\mathrm{a}, *}$ \\ a Department of Genetics and Pathology, Rudbeck Laboratory, Uppsala University, SE-751 85 Uppsala, Sweden \\ b Department of Oncology, Radiology and Clinical Immunology, Uppsala University, Uppsala, Sweden \\ ${ }^{\mathrm{c}}$ Department of Laboratory Medicine, Stem Cell Center, Hematology and Transplantation, Lund University, Lund, Sweden \\ d Department of Hematology, Karolinska Institutet, Stockholm, Sweden \\ e Department of Medical Sciences (Hematology), Uppsala University, Uppsala, Sweden \\ ${ }^{\mathrm{f}}$ Departments of Hematology/Oncology, Karolinska University Hospital, Stockholm, Sweden \\ ${ }^{g}$ Department of Oncology and Pathology, Karolinska Institutet, Stockholm, Sweden \\ h Department of Epidemiology Research, Statens Serum Institut, Copenhagen, Denmark \\ i Department of Hematology, The Leukemia Laboratory, Rigshospitalet, Copenhagen, Denmark
}

\section{A R T I C L E I N F O}

\section{Article history:}

Received 18 April 2009

Received in revised form 3 June 2009

Accepted 4 June 2009

Available online 1 July 2009

\section{Keywords:}

MDM2 SNP309

Chronic lymphocytic leukemia

Binet stage

IGHV mutational status

Genomic aberrations

Prognostic markers

\begin{abstract}
A B S T R A C T
The 309T>G polymorphism in the promoter region of the MDM2 gene, known as SNP309, has recently been suggested as an unfavorable prognostic marker in chronic lymphocytic leukemia (CLL) although this has been questioned. To investigate this further, we analyzed the MDM2 SNP309 genotypes in 418 CLL patients and correlated the results with established CLL prognostic factors, time to treatment and overall survival. In this Swedish cohort, no association existed between any particular MDM2 SNP309 genotype, overall survival and time to treatment. Furthermore, no correlation was shown between the MDM2 SNP309 genotypes and Binet stage, IGHV mutational status and recurrent genomic aberrations. In summary, this study argues against the use of the MDM2 SNP309 as a prognostic marker in CLL.
\end{abstract}

(c) 2009 Elsevier Ltd. All rights reserved.

\section{Introduction}

Chronic lymphocytic leukemia (CLL) is a heterogeneous disease with varying clinical outcome, where many patients have an indolent course for many years, whereas others show a more aggressive disease despite treatment. In recent years, the immunoglobulin variable heavy-chain (IGHV) gene mutational status and FISH analysis of certain genomic aberrations $(11 \mathrm{q}-,+12,13 \mathrm{q}-$ and $17 \mathrm{p}-$ ) have shown to be robust prognostic markers in CLL [1-3]. To date however, the genetic factors which influence the clinical heterogeneity in this malignancy are not fully elucidated.

The murine double minute 2 (MDM2), mapped on chromosome $12 \mathrm{q} 13-14$, is an important regulator of the tumor suppressor pro-

\footnotetext{
* Corresponding author at: Department of Genetics and Pathology, Rudbeck Laboratory, Uppsala University, SE-751 85 Uppsala, Sweden. Tel.: +46 1861159 47; fax: +4618554025.

E-mail address: richard.rosenquist@genpat.uu.se (R. Rosenquist).
}

tein p53 and functions by suppressing p53 transcriptional activity through binding of the p53 transactivation domain [4]. In addition, MDM2 promotes proteasome-mediated degradation of p53 [5]. Since the $\mathrm{p} 53$ functions are crucial for tumor suppression, excessive down regulation by MDM2 renders the cells susceptible to neoplastic lesions [6]. Furthermore, p53-independent functions of MDM2 in tumorigenesis have also been described [7], making MDM2 an important player in cancer development.

A polymorphism positioned at nucleotide 309 in the first intron region of the MDM2 gene (SNP309, rs2279744) has been previously demonstrated to affect p53 function [8]. The study showed that the presence of the homozygous GG genotype in cell lines elevates the expression of MDM2 protein compared to those with TT genotype [8]. This was due to the increased binding affinity of the MDM2 transcriptional activator Sp1 within cell lines with GG genotype. The increased level of MDM2 in turn, is thought to cause inability to stabilize p53 in stressed cells, which may lead to insufficient DNA repair, reduced apoptosis and faster tumor formation [8]. In addition, the presence of GG genotype has also been associated with 
poor outcome in several human cancers, including breast cancer [9], renal cell carcinoma [10], Li-Fraumeni syndrome [11] and oral carcinoma [12]. Furthermore, the presence of GG genotype of the MDM2 SNP309 has been correlated with early tumor onset among patients with Li-Fraumeni syndrome [8] and colorectal carcinoma [13].

Previous studies on the effects of the MDM2 SNP309 on clinical outcome in CLL have shown conflicting results. The first reported study, which was performed on small cohort CLL patients (83 cases), did not reveal any effect of the different genotypes on clinical outcome [14]. A subsequent larger study, including two independent CLL cohorts (140 and 111 cases), implicated the MDM2 SNP309 to affect outcome in CLL, where patients carrying the TG/GG genotypes had significantly shorter overall survival compared to TT carriers, while more progressive disease was indicated in patients carrying GG genotype compared to those with TT/TG genotypes [15]. In addition, the investigators demonstrated that the MDM2 SNP309 could be applied as a prognostic factor independently of IGHV mutational status, CD38, ZAP-70 and Rai staging. However, these findings could not be verified in a large German CLL cohort (617 cases), as reported by Zenz et al. [16], as they did not observe any significant difference in time to first treatment and overall survival.

Since the relevance of the MDM2 SNP309 as an unfavorable prognostic marker remains arguable, we here investigated the prognostic role of this SNP in our CLL cohort comprising 418 cases. We also studied the relation of the MDM2 SNP309 to other known prognostic markers.

\section{Materials and methods}

\subsection{Patients and materials}

A total of 418 Swedish CLL patients were included in the current study; 175 patients from Uppsala University Hospital, Uppsala, Karolinska University Hospital, Stockholm and Umeå University Hospital, Umeå and 243 CLL patients from the Swedish part of a population-based case-control study called SCALE (Scandinavian Lymphoma Etiology) [17]. Tumor material was obtained predominantly from peripheral blood ( 340 cases) and bone marrow ( 48 cases). In addition, tumor samples were also collected from lymph nodes ( 26 cases) and spleen ( 4 cases). Samples displayed the typical CLL immunophenotype $\left(\mathrm{CD}^{+} / \mathrm{CD} 19^{+} / \mathrm{CD} 23^{+}\right)$and met the diagnostic criteria presented by the International Workshop on Chronic Lymphocytic Leukemia (IWCLL) [18]. Informed consent was obtained according to the Declaration of Helsinki and ethical approval by the local ethical review committee.

Survival data was available on all 418 patients, with a median follow-up time of 111 months (quartile range, 60-162 months), while data on time to treatment was available for 287 patients. Binet data was available for 306 patients, with 222 patients classified as Binet stage A, 58 as stage B and 26 as stage C.

\subsection{Analysis of the MDM2 SNP309 polymorphism}

Genomic DNA was extracted from frozen tumor cells as previously described [19]. DNA was whole-genome amplified according to the manufacturer's protocol (GenomiPhi DNA Amplification, GE Healthcare, Uppsala, Sweden). Identification of the MDM2 SNP309 genotype was performed using the PCR-restriction fragment length polymorphism (RFLP) method as previously described by Hirata et al. [10], with slight modifications. Briefly, PCR amplification was performed in a $25 \mu \mathrm{l}$ reaction volume consisting of $100 \mathrm{ng}$ of whole-genome amplified DNA, $800 \mathrm{mM}$ dNTP, 1 unit of Hotstar Taq polymerase (Qiagen GmBH, Hilden, Germany), and $2 \mathrm{mM}$ of each forward (5'-CTGCCCACTGAACCGGC-3') and reverse primers ( $5^{\prime}$ GAGGTCTCCGCGGGAGTTC-3'). The amplification program comprised of $10 \mathrm{~min}$ of denaturing at $95^{\circ} \mathrm{C}$, followed by 30 cycles of $30 \mathrm{~s}$ at $95^{\circ} \mathrm{C}, 30 \mathrm{~s}$ at $57^{\circ} \mathrm{C}$ and $1 \mathrm{~min}$ at $72{ }^{\circ} \mathrm{C}$, with a final step at $72^{\circ} \mathrm{C}$ for $7 \mathrm{~min}$. For RFLP analysis, the PCR product was MSPA1I (New England Biolabs GmbH, Frankfurt am Main, Germany) digested, according to the manufacturer's protocol and visualized on $2 \%$ agarose gel. A homozygous TT genotype was verified by a $145 \mathrm{bp}$ long fragment. The heterozygous TG genotype produced three fragments ( $145 \mathrm{bp}, 99 \mathrm{bp}$ and $46 \mathrm{bp}$ in size), while the homozygous GG genotype demonstrated two fragments ( $99 \mathrm{bp}$ and $46 \mathrm{bp}$ ).

To verify that the whole-genome amplification process had not caused any false genotyping results, we subjected original genomic DNA from 20 randomly selected samples to the similar genotyping process as mentioned above. We could not detect any differences in genotypes between genomic and whole-genome amplified DNA.

\subsection{Assessment of IGHV gene mutational status}

The IGHV gene mutational status was assessed by PCR amplification with IGHV gene family-specific primers, followed by sequence analysis as previously described $[20,21]$. Sequences were submitted to IMGT/V-QUEST $[22,23]$ and GenBank/IgBlast to determine the IGHV identity. The IGHV gene was considered mutated when the identity to the corresponding germline gene was less than $98 \%$.

\subsection{Analysis of recurrent genomic aberrations}

Cytogenetic screening for recurrent genomic aberrations was performed on 150 patients samples using a commercial CLL FISH probe panel (VYSIS, Downers Grove, IL, USA) to detect $\operatorname{del}(17)(\mathrm{p} 13),+12, \operatorname{del}(11)(\mathrm{q} 22)$, and $\operatorname{del}(13)(\mathrm{q} 14)$. At least 200 interphase nuclei were analyzed for each probe and tumor sample. The cutoff of an aberration was set at $>10 \%$. In addition, 130 CLL samples were analyzed using highresolution Affymetrix 250K SNP-arrays from which we extracted data on known recurrent genomic aberrations, as described in a previous study [24].

\subsection{Statistical analysis}

All statistical analyses were carried out using Statistica version 8 (Stat Soft, US). Fisher's exact test or Chi-square $\left(\chi^{2}\right)$ test were employed to determine the significance of differences in genotype usage between patient groups. Comparison of median age at diagnosis between patients with different genotypes was carried out using the Kruskal-Wallis test. Overall survival time was measured from the date of diagnosis to either the last follow-up date (defined as censored) or death. Time to treatment was evaluated by the time interval from the diagnostic date until date of initial treatment. The Kaplan-Meier analysis was performed to construct survival curves for overall survival and time to treatment. Differences in median time to treatment and overall survival between groups were evaluated using the log-rank test.

Univariate Cox proportional hazards model was applied to evaluate the possible association between single risk factors (i.e. sex, age at diagnosis, Binet stage MDM2 SNP309 genotype, IGHV mutational status, and genomic aberrations) with overall survival. Variables found to be statistically significant $(p<0.05)$ in the univariate analysis were subsequently included in a multivariate Cox proportional hazards model to evaluate the relationship between the variables.

\section{Results}

\subsection{MDM2 SNP309 genotype distribution}

Out of 418 CLL cases included in the study, 44.2\% (185 cases) showed the TT genotype of the MDM2 SNP309, whereas 45.5\% (190 cases) displayed a heterozygous genotype and 10.3\% (43 cases) were found to carry the GG genotype. There was no difference in median age at diagnosis for patients with the TT, TG and GG genotypes (64, 65 and 64 years, respectively). The MDM2 SNP309 genotype distribution in our cohort was in accordance with the Hardy-Weinberg equilibrium and was comparable to recently published studies [15,16].

\subsection{SNP309 genotype and prognosis}

Comparison of overall survival between patients with the different MDM2 SNP309 genotypes revealed no significant difference (Fig. 1). The median survival was 112 months (range, 60-161 months), 111 months (range, 61-157 months) and 90 months (range, 46-142 months) for patients with the SNP309 TT, TG and GG genotypes, respectively. Furthermore, Kaplan-Meier analysis of time to treatment did not reveal any significant difference between patients with TT, TG and GG genotypes (Fig. 2). The median time to treatment for patients with SNP309 TT, TG and GG genotypes were 25 months (range, 6-107 months), 70 months (range, 5-132 months) and 20 months (range, 4-74 months), respectively.

The MDM2 SNP309 genotypes were then grouped into T+ alleles (combining the $\mathrm{T} / \mathrm{T}$ and $\mathrm{T} / \mathrm{G}$ genotypes into one group) and alleles encompassing the GG genotype. Analysis of time to treatment between the dichotomized groups failed to indicate any significant difference between the two groups ( $p=0.167$, data not shown). In addition, overall survival analysis showed no significant difference between dichotomized groups ( $p=0.263$, data not shown). When 


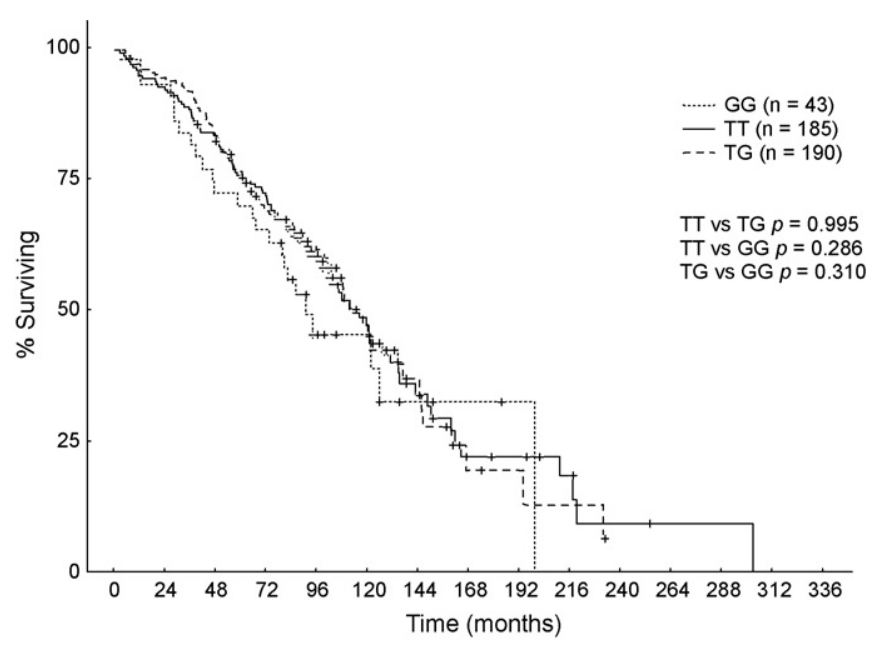

Fig. 1. Overall survival for CLL patients according to the MDM2 SNP309 polymorphism status. No significant difference was indicated by log-rank test between the genotypes indicated.

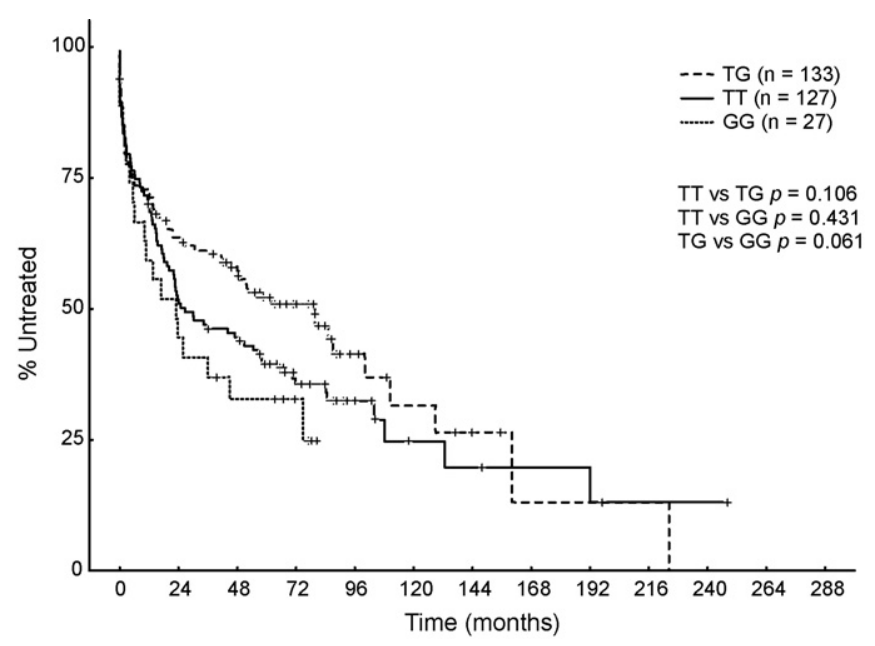

Fig. 2. Time to treatment analysis for CLL patients according to the MDM2 SNP309 polymorphism status. No significant difference was indicated by log-rank test between any of the genotypes indicated. studying Binet stage A patients only, no differences were observed in overall survival or time to treatment in patients with different MDM2 SNP309 genotypes (data not shown).

\subsection{MDM2 SNP309 genotype and relation to IGHV mutational status, Binet stage and genomic aberrations}

In line with earlier reports [1,3], overall survival and time to treatment analysis on the current cohort of CLL confirmed unmutated IGHV genes, Binet stages B and C as well as presence of $17 p$ deletion, $11 \mathrm{q}$ deletion and trisomy 12 as prognostic markers predicting poor clinical outcome (Table 2 ).

On the other hand, the MDM2 SNP309 genotype distribution showed no significant difference in relation to Binet stage, IGHV mutation status and presence of recurrent genomic aberrations, except for trisomy 12 (Table 1 ). In addition, we did not observe any influence of the MDM2 SNP309 genotype on overall survival and time to treatment according to IGHV mutational status, Binet stage and type of genomic aberration subgroups (data not shown).

We next performed a Cox proportional hazards regression analysis to identify independent prognostic indicator for overall survival. In univariate analysis, age at diagnosis, gender, Binet stage, IGHV mutational status and genomic aberrations significantly influenced overall survival (Table 3 ), and in multivariate analysis, all factors except gender remained significant (Table 3).The SNP309 showed no significant association with prognosis when analyzed in univariate analysis and was subsequently not included in multivariate analysis.

\section{Discussion}

The relevance of the MDM2 SNP309 genotype as a prognostic marker in CLL has been suggested in recent findings by Gryshchenko et al. [15]. These authors showed that the MDM2 SNP309 G allele correlated to inferior disease outcome, where CLL patients with the GG genotype had shorter overall survival and time to treatment. In addition, based on regression analysis between the SNP309 genotypes and other prognostic markers, e.g. IGHV mutational status, CD38, ZAP-70 expression and Rai stage, the investigators identified MDM2 SNP309 as an independent marker for prediction of treatment-free survival in CLL. They also observed that the effect of MDM2 SNP309 on progression, at least partly depended on the

Table 1

Clinical data of the current cohort of CLL cases genotyped for the MDM2 SNP309 polymorphism.

\begin{tabular}{|c|c|c|c|c|c|}
\hline Variable & All patients & $\mathrm{TT}$ & TG & GG & $p$ value $^{*}$ \\
\hline No. of patients (\%) & 418 & $185(44.2 \%)$ & $190(45.5 \%)$ & $43(10.3 \%)$ & \\
\hline Median age at diagnosis (years) & & 64 & 65 & 64 & $\mathrm{NS}^{\mathrm{a}}$ \\
\hline Binet stage & 306 & & & & \\
\hline A & $222(72.5 \%)$ & $101(45.5 \%)$ & $96(43.2 \%)$ & $25(11.3 \%)$ & NS \\
\hline B & $58(19.0 \%)$ & $29(50.0 \%)$ & $22(37.9 \%)$ & $7(12.1 \%)$ & NS \\
\hline C & $26(8.5 \%)$ & $11(42.3 \%)$ & $11(42.3 \%)$ & $4(15.4 \%)$ & NS \\
\hline IGHV mutation status & 409 & & & & \\
\hline Mutated IGHV gene & $239(58.4 \%)$ & $106(44.4 \%)$ & $114(47.7 \%)$ & $19(7.9 \%)$ & NS \\
\hline Unmutated IGHV gene & $170(41.6 \%)$ & $77(45.3 \%)$ & $69(40.6 \%)$ & $24(14.1 \%)$ & NS \\
\hline Genomic aberrations & 280 & & & & \\
\hline No aberration & $65(23.3 \%)$ & $19(29.2 \%)$ & $35(53.8 \%)$ & $11(16.9 \%)$ & NS \\
\hline $13 q$ deletion & $128(45.7 \%)$ & $63(49.2 \%)$ & $56(43.8 \%)$ & $9(7.0 \%)$ & NS \\
\hline 11q deletion & $40(14.3 \%)$ & $16(40.0 \%)$ & $20(50.0 \%)$ & $4(10.0 \%)$ & NS \\
\hline $17 p$ deletion & $20(7.1 \%)$ & $8(40.0 \%)$ & $9(45.0 \%)$ & $3(15.0 \%)$ & NS \\
\hline Trisomy 12 & $27(9.6 \%)$ & $14(51.8 \%)$ & $9(33.3 \%)^{b}$ & $4(14.8 \%)$ & 0.02 \\
\hline
\end{tabular}

* Comparisons were made against the total number of the CLL patients for each genotype.

NS = not significant between groups by either the $\chi^{2}$ test or the Fisher's exact test.

a NS: not significant between groups by Kruskal-Wallis test.

b Due to the limitations of genotyping methods, TTG and TGG genotypes were not distinguishable. 
Table 2

Overall survival and time to treatment data of the current cohort of CLL cases according to Binet stage, IGHV mutation status and recurrent genomic aberrations.

\begin{tabular}{|c|c|c|c|c|c|c|c|c|c|c|}
\hline \multirow[t]{3}{*}{ Variable } & \multicolumn{5}{|c|}{ Overall survival } & \multicolumn{5}{|c|}{ Time to treatment } \\
\hline & \multirow[t]{2}{*}{ Valid, $N$} & \multirow[t]{2}{*}{ Median (months) } & \multicolumn{2}{|c|}{$\begin{array}{l}\text { Interquartile } \\
\text { ranges (months) }\end{array}$} & \multirow[t]{2}{*}{$p$ value } & \multirow[t]{2}{*}{ Valid, $N$} & \multirow[t]{2}{*}{ Median (months) } & \multicolumn{2}{|c|}{$\begin{array}{l}\text { Interquartile } \\
\text { ranges (months) }\end{array}$} & \multirow[t]{2}{*}{$p$ value } \\
\hline & & & $25 \%$ & $75 \%$ & & & & $25 \%$ & $75 \%$ & \\
\hline Binet stage & 306 & & & & & 241 & & & & \\
\hline A & 222 & 142 & 84 & 209 & & 175 & 79 & 21 & 140 & \\
\hline B & 58 & 72 & 41 & 92 & & 45 & 2 & 1 & 11 & \\
\hline $\mathrm{C}$ & 26 & 47 & 35 & 90 & $<.001^{\mathrm{a}}$ & 21 & 0 & 0 & 4 & $<.001^{\mathrm{a}}$ \\
\hline IGHV mutational status & 409 & & & & & 282 & & & & \\
\hline Mutated IGHV gene & 239 & 146 & 105 & 210 & & 170 & 102 & 17 & 163 & \\
\hline Unmutated IGHV gene & 170 & 70 & 42 & 101 & $<.001$ & 112 & 14 & 2 & 35 & $<.001$ \\
\hline Genomic aberrations & 280 & & & & & 226 & & & & \\
\hline No aberration & 65 & 129 & 92 & 177 & & 51 & Not achieved & 15 & Not achieved & \\
\hline 13q deletion & 128 & 121 & 99 & 220 & & 104 & 91 & 19 & 149 & \\
\hline 11q deletion & 40 & 71 & 46 & 111 & & 33 & 4 & 1 & 40 & \\
\hline 17p deletion & 20 & 58 & 31 & 120 & & 15 & 5 & 1 & 45 & \\
\hline Trisomy 12 & 27 & 77 & 49 & 109 & $<.001^{\mathrm{b}}$ & 23 & 16 & 1 & 39 & $<.001^{\mathrm{b}}$ \\
\hline
\end{tabular}

a Log-rank test was made to compare between Binet stage A against combined stages B and C.

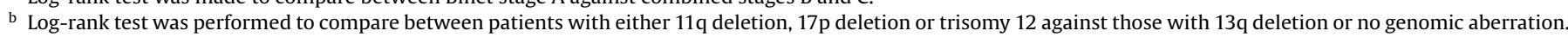

Table 3

Cox regression analysis of overall survival.

\begin{tabular}{|c|c|c|c|c|c|c|c|c|}
\hline \multirow[t]{2}{*}{ Variable } & \multirow[t]{2}{*}{ Comparison } & \multirow[t]{2}{*}{ Valid, $N$} & \multicolumn{3}{|c|}{ Univariate analysis } & \multicolumn{3}{|c|}{ Multivariate analysis } \\
\hline & & & HR & $95 \% \mathrm{CI}$ & $p$ value & HR & $95 \% \mathrm{CI}$ & $p$ value \\
\hline Age at diagnosis & $\leq 65$ vs. $>65$ years old & 418 & 1.77 & $1.34-2.34$ & $<0.0001$ & 2.10 & $1.38-3.19$ & 0.0005 \\
\hline Gender & Female vs. male & 418 & 1.47 & $1.08-1.98$ & 0.01 & 1.62 & $0.99-2.67$ & 0.054 \\
\hline Binet stage & A vs. $B+C$ & 307 & 3.67 & $2.64-5.11$ & $<0.0001$ & 3.39 & $2.19-5.22$ & $<0.0001$ \\
\hline IGHV mutational status & Mutated vs. unmutated & 409 & 3.73 & $2.81-4.95$ & $<0.0001$ & 3.20 & $1.89-5.40$ & $<0.0001$ \\
\hline Genomic aberration & $\begin{array}{l}\text { Normal + del }(13 q) \text { vs. } \\
\operatorname{del}(17 p)+\operatorname{del}(11 q)+\text { trisomy } 12\end{array}$ & 280 & 3.04 & $2.13-4.34$ & $<0.0001$ & 2.32 & $1.45-3.71$ & 0.0004 \\
\hline \multirow[t]{2}{*}{ MDM2 SNP309 } & TT/TG vs. GG & 418 & 1.27 & $0.84-1.94$ & 0.2 & \multirow{2}{*}{\multicolumn{3}{|c|}{ Not included }} \\
\hline & TT vs. GG/TG & 418 & 1.05 & $0.80-1.38$ & 0.7 & & & \\
\hline
\end{tabular}

Abbreviations: HR, hazard ratio; CI, confidence interval.

p53 status in a gene-dosage fashion, since both TG and GG genotypes correlated significantly with reduced treatment-free survival in patients with monoallelic loss of 17p. Furthermore, the presence of the $G$ allele was shown to increase the MDM2 protein expression levels in CLL cells [15].

However, no significant difference was observed in time to treatment or overall survival among patients with the different genotypes in the present study. Thus, we found no support for an influence of MDM2 SNP309 on clinical outcome in CLL patients. Likewise, no correlation was apparent between the different MDM2 SNP309 genotypes and Binet stage, IGHV mutation status or genomic aberrations. It was noted that the distribution of SNP309 genotypes were significantly different in patients with trisomy 12 . However, the relevance of this finding, if any, is unknown. Moreover, we addressed whether the MDM2 SNP309 correlates with CLL age at diagnosis, since such observations were reported in other types of cancers $[8,13]$. Comparison of age at diagnosis between patients with different MDM2 SNP309 did not reveal any significant difference.

In line with our findings, Zenz et al. [16] have also been unable to detect any influence of the MDM2 SNP309 on either overall survival or disease progression. Additionally, no correlation was found between the polymorphism and either Binet stage or other molecular prognostic factors in CLL, such as genomic aberrations and IGHV mutational status. Furthermore, the authors also argued against the postulated effect of the MDM2 SNP309 on the expression of MDM2 protein itself, since no significant difference in MDM2 mRNA levels based on the SNP309 genotype was found [16].

In conclusion, the MDM2 SNP309 does not appear to influence the clinical course in CLL and should not be considered as a new prognostic marker for outcome prediction. In recent years, a number of SNPs have been suggested as useful prognostic markers in CLL. The presence of certain SNPs within the BAX [25], P2X7 [26], GNAS1 [27] and BCL2 [28] genes have been associated to disease progression and inferior survival for the patients. However, none of these potential SNPs have been confirmed in subsequent investigations by other groups [19,29-32]. Thus, it is important that any potential SNP should be verified by large independent cohorts and independent research centers.

\section{Conflict of interest}

The authors report no potential conflicts of interest.

\section{Authorship and disclosures}

MAK performed research, analyzed data and wrote the paper; MM and NZ analyzed data and wrote the paper; NC, RG, MJ and JJ provided associated phenotypic and molecular data; EK, Å̊, JL and GJ provided clinical data, BG and MM provided samples and associated data, RR supervised the research and wrote the paper.

\section{Acknowledgements}

This study was supported by grants from the Nordic Cancer Union, the Swedish Cancer Society, the Swedish Society for Medical Research and Lion's Cancer Research Foundation, Uppsala, and grant 1 R03 CA 101496-01 from the National Institutes of Health (SCALE study). This research was also funded by the Fellowship 
(2006/18) awarded to R. Rosenquist by the European Hematology Association.

We thank Prof. Göran Roos and Dr. Mats Merup for providing samples and clinical data, and the Swedish CLL group for support during the collection of clinical data.

\section{References}

[1] Hamblin TJ, Davis Z, Gardiner A, Oscier DG, Stevenson FK. Unmutated Ig V(H) genes are associated with a more aggressive form of chronic lymphocytic leukemia. Blood 1999;94:1848-54.

[2] Damle RN, Wasil T, Fais F, Ghiotto F, Valetto A, Allen SL, et al. Ig V gene mutation status and CD38 expression as novel prognostic indicators in chronic lymphocytic leukemia. Blood 1999;94:1840-7.

[3] Dohner H, Stilgenbauer S, Benner A, Leupolt E, Krober A, Bullinger L, et al. Genomic aberrations and survival in chronic lymphocytic leukemia. N Engl J Med 2000;343:1910-6.

[4] Momand J, Zambetti GP, Olson DC, George D, Levine AJ. The MDM-2 oncogene product forms a complex with the $\mathrm{p} 53$ protein and inhibits $\mathrm{p} 53$-mediated transactivation. Cell 1992;69:1237-45.

[5] Honda R, Tanaka H, Yasuda H. Oncoprotein MDM2 is a ubiquitin ligase E3 for tumor suppressor p53. FEBS Lett 1997;420:25-7.

[6] Watanabe T, Hotta T, Ichikawa A, Kinoshita T, Nagai H, Uchida T, et al. The MDM2 oncogene overexpression in chronic lymphocytic leukemia and low-grade lymphoma of B-cell origin. Blood 1994;84:3158-65.

[7] Bouska A, Lushnikova T, Plaza S, Eischen CM. Mdm2 promotes genetic instability and transformation independent of p53. Mol Cell Biol 2008;28:4862-74.

[8] Bond GL, Hu W, Bond EE, Robins H, Lutzker SG, Arva NC, et al. A single nucleotide polymorphism in the MDM2 promoter attenuates the p53 tumor suppressor pathway and accelerates tumor formation in humans. Cell 2004;119:591-602.

[9] Boersma BJ, Howe TM, Goodman JE, Yfantis HG, Lee DH, Chanock SJ, et al. Association of breast cancer outcome with status of p53 and MDM2 SNP309. J Natl Cancer Inst 2006;98:911-9.

[10] Hirata H, Hinoda Y, Kikuno N, Kawamoto K, Suehiro Y, Tanaka Y, et al. MDM2 SNP309 polymorphism as risk factor for susceptibility and poor prognosis in renal cell carcinoma. Clin Cancer Res 2007;13:4123-9.

[11] Ruijs MW, Schmidt MK, Nevanlinna H, Tommiska J, Aittomaki K, Pruntel $\mathrm{R}$, et al. The single-nucleotide polymorphism 309 in the MDM2 gene contributes to the Li-Fraumeni syndrome and related phenotypes. Eur J Hum Genet 2007; $15: 110-4$

[12] Tu HF, Chen HW, Kao SY, Lin SC, Liu CJ, Chang KW. MDM2 SNP 309 and p53 codon 72 polymorphisms are associated with the outcome of oral carcinoma patients receiving postoperative irradiation. Radiother Oncol 2008;87: 243-52.

[13] Bond GL, Menin C, Bertorelle R, Alhopuro P, Aaltonen LA, Levine AJ. MDM2 SNP309 accelerates colorectal tumour formation in women. J Med Genet 2006;43:950-2.

[14] Lahiri O, Harris S, Packham G, Howell M. p53 pathway gene single nucleotide polymorphisms and chronic lymphocytic leukemia. Cancer Genet Cytogenet 2007;179:36-44.

[15] Gryshchenko I, Hofbauer S, Stoecher M, Daniel PT, Steurer M, Gaiger A, et al. MDM2 SNP309 is associated with poor outcome in B-cell chronic lymphocytic leukemia. J Clin Oncol 2008;26:2252-7.

[16] Zenz T, Habe S, Benner A, Kienle D, Dohner H, Stilgenbauer S. The MDM2$309 \mathrm{~T} / \mathrm{G}$ promoter single nucleotide polymorphism does not alter disease characteristics in chronic lymphocytic leukemia. Haematologica 2008;93: 1111-3.
[17] Smedby KE, Hjalgrim H, Melbye M, Torrang A, Rostgaard K, Munksgaard L, et al. Ultraviolet radiation exposure and risk of malignant lymphomas. J Natl Cancer Inst 2005;97:199-209.

[18] Hallek M, Cheson BD, Catovsky D, Caligaris-Cappio F, Dighiero G, Dohner H, et al. Guidelines for the diagnosis and treatment of chronic lymphocytic leukemia: a report from the International Workshop on Chronic Lymphocytic Leukemia updating the National Cancer Institute-Working Group 1996 guidelines. Blood 2008;111:5446-56.

[19] Skogsberg S, Tobin G, Krober A, Kienle D, Thunberg U, Aleskog A, et al. The G(248)A polymorphism in the promoter region of the Bax gene does not correlate with prognostic markers or overall survival in chronic lymphocytic leukemia. Leukemia 2006;20:77-81.

[20] Tobin G, Thunberg U, Johnson A, Eriksson I, Soderberg O, Karlsson K, et al. Chronic lymphocytic leukemias utilizing the VH3-21 gene display highly restricted Vlambda2-14 gene use and homologous CDR3s: implicating recognition of a common antigen epitope. Blood 2003;101:4952-7.

[21] van Dongen JJ, Langerak AW, Bruggemann M, Evans PA, Hummel M, Lavender FL, et al. Design and standardization of PCR primers and protocols for detection of clonal immunoglobulin and T-cell receptor gene recombinations in suspect lymphoproliferations: report of the BIOMED-2 Concerted Action BMH4-CT983936. Leukemia 2003;17:2257-317.

[22] Giudicelli V, Chaume D, Lefranc MP. IMGT/V-QUEST, an integrated software program for immunoglobulin and T cell receptor V-J and V-D-J rearrangement analysis. Nucleic Acids Res 2004;32:W435-40.

[23] Lefranc MP, Giudicelli V, Kaas Q, Duprat E, Jabado-Michaloud J, Scaviner D, et al. IMGT, the international ImMunoGeneTics information system. Nucleic Acids Res 2005;33:D593-7.

[24] Gunnarsson R, Staaf J, Jansson M, Ottesen AM, Goransson H, Liljedahl U, et al. Screening for copy-number alterations and loss of heterozygosity in chronic lymphocytic leukaemia-a comparative study of four differently designed, high resolution microarray platforms. Genes Chromosomes Cancer 2008;47:697-711.

[25] Saxena A, Moshynska O, Sankaran K, Viswanathan S, Sheridan DP. Association of a novel single nucleotide polymorphism, G(-248)A, in the $5^{\prime}$-UTR of BAX gene in chronic lymphocytic leukemia with disease progression and treatment resistance. Cancer Lett 2002;187:199-205.

[26] Thunberg U, Tobin G, Johnson A, Soderberg O, Padyukov L, Hultdin M, et al. Polymorphism in the P2X7 receptor gene and survival in chronic lymphocytic leukaemia. Lancet 2002;360:1935-9.

[27] Frey UH, Nuckel H, Sellmann L, Siemer D, Kuppers R, Durig J, et al. The GNAS1 T393C polymorphism is associated with disease progression and survival in chronic lymphocytic leukemia. Clin Cancer Res 2006;12:5686-92.

[28] Nuckel H, Frey UH, Bau M, Sellmann L, Stanelle J, Durig J, et al. Association of a novel regulatory polymorphism $(-938 \mathrm{C}>\mathrm{A})$ in the BCL2 gene promoter with disease progression and survival in chronic lymphocytic leukemia. Blood 2007;109:290-7.

[29] Starczynski J, Pepper C, Pratt G, Hooper L, Thomas A, Hoy T, et al. The P2X7 receptor gene polymorphism $1513 \mathrm{~A} \rightarrow \mathrm{C}$ has no effect on clinical prognostic markers, in vitro sensitivity to fludarabine, $\mathrm{Bcl}-2$ family protein expression or survival in B-cell chronic lymphocytic leukaemia. Br J Haematol 2003;123:66-71.

[30] Kaderi MA, Murray F, Jansson M, Merup M, Karlsson K, Roos G, et al. The GNAS1 T393C polymorphism and lack of clinical prognostic value in chronic lymphocytic leukemia. Leuk Res 2008;32:984-7.

[31] Kaderi MA, Norberg M, Murray F, Merup M, Sundstrom C, Roos G, et al. The BCL-2 promoter $(-938 \mathrm{C}>\mathrm{A})$ polymorphism does not predict clinical outcome in chronic lymphocytic leukemia. Leukemia 2008;22:339-43.

[32] Majid A, Tsoulakis O, Walewska R, Gesk S, Siebert R, Kennedy DB, et al. BCL2 expression in chronic lymphocytic leukemia: lack of association with the BCL2 $938 \mathrm{~A}>\mathrm{C}$ promoter single nucleotide polymorphism. Blood 2008;111:874-7. 